\title{
Compreensão do Conceito de Razão por Futuros Educadores e Professores dos Primeiros Anos de Escolaridade
}

\author{
The Prospective Kindergarten and Elementary School Teachers' \\ Understanding of the Ratio Concept
}

\author{
José António Fernandes ${ }^{*}$ \\ Laurinda Leite ${ }^{* *}$
}

\begin{abstract}
Resumo
Este artigo centra-se na compreensão que futuros educadores e professores dos primeiros anos de escolaridade evidenciam do conceito de razão. No estudo participaram 81 estudantes do $2^{\circ}$ ano da Licenciatura em Educação Básica, de uma universidade portuguesa, aos quais foi aplicado um questionário, incidindo em quatro dimensões: significado de razão; usos do conceito de razão; representação simbólica de razão; e representações para explicação do conceito de razão. Em termos de resultados, as maiores frequências foram obtidas para a: ideia de razão como comparação/relação entre grandezas; crença em que o conceito de razão pode ser usado em contextos diversificados; crença em que pode ser representado através de operações envolvendo letras, números ou apenas os sinais das operações, quando é pedida a sua representação simbólica, e através de diagramas e representações gráficas, quando é solicitada a descrição da sua explicação. Estes resultados revelam fragilidades no conhecimento matemático dos estudantes, sobretudo no que se refere à definição do conceito de razão e às suas representações.
\end{abstract}

Palavras-chave: Conceções sobre Razão. Representações de Razão. Futuros Educadores e Professores dos Primeiros Anos de Escolaridade.

\begin{abstract}
This paper focuses on the prospective kindergarten and elementary school teachers' understanding of the ratio concept. Eighty-one undergraduates preparing to become kindergarten and primary school teachers, in a Portuguese university, participated in the study. They answered to a questionnaire aiming at evaluating their understanding of the ratio concept based on four dimensions: meaning of ratio; use of the ratio concept; symbolic representations of ratio; and representations for explaining the ratio concept. As far as results are concerned, the highest frequencies were obtained for: the idea of ratio as a comparison/relationship between two magnitudes; the belief that this concept is used in several contexts; the belief that it can be represented through operations with letters, figures or operation signals, as in symbolic representations; and through diagrams and graphical

*Doutor em Educação pela Universidade do Minho, Braga, Portugal. Professor Associado de Educação Matemática, do Departamento de Estudos Integrados de Literacia, Didática e Supervisão, no Instituto de Educação, da Universidade do Minho, Braga, Portugal. Endereço para correspondência: Campus de Gualtar, Braga - Portugal, CEP: 4710-057.E-mail: jfernandes@ie.uminho.pt

** Doutora em Educação pela Universidade do Minho, Braga, Portugal. Professora Catedrática de Educação em Ciências, do Departamento de Estudos Integrados de Literacia, Didática e Supervisão, no Instituto de Educação, da Universidade do Minho, Braga, Portugal. Endereço para correspondência: Campus de Gualtar, Braga Portugal, CEP: 4710-057. E-mail: 1leite@ie.uminho.pt
\end{abstract}


representations, as in representations for explaining the ratio concept. The results show weaknesses in prospective teachers' mathematical knowledge of ratio, namely with regard to its definition and representations.

Keywords: Conceptions of Ratio. Representations of Ratio. Prospective Kindergarten and Elementary School Teachers.

\section{Introdução}

Nos programas escolares de Matemática do Ensino Básico e do Ensino Secundário portugueses, o tema razão não é tratado de forma explícita e independente, mas está presente, desde os primeiros anos de escolaridade ( $1^{\circ}$ e $2^{\circ}$ ciclos do Ensino Básico), em diversos conteúdos com que se relaciona. No caso do programa do Ensino Básico (MINISTÉRIO DA EDUCAÇÃO E CIÊNCIA, 2012, 2013), constata-se que no $2^{\circ}$ ano são introduzidas as frações (em casos simples), no $3^{\circ}$ ano inicia-se a representação de frações na reta numérica, no $4^{\circ}$ ano é introduzida a noção de percentagem e no $6^{\circ}$ ano começam a estudar a proporcionalidade.

No programa do $3^{\circ}$ ciclo do Ensino Básico (incluindo as metas curriculares), o termo razão é relacionado com variados conteúdos, designadamente: razão de dois números; razão de perímetros de figuras semelhantes; razão de áreas de figuras semelhantes; razão trigonométrica; e razão de homotetia.

A presença do conceito de razão nos programas escolares, ainda que sem constituir um tema separado, e as suas muitas conexões com outros temas matemáticos evidencia a importância da formação dos alunos, futuros educadores e professores nesse conceito. Essa importância reforça-se na medida em que, frequentemente, os planos de estudos dos cursos frequentados por estes alunos não contemplam, explicitamente, o conceito de razão e alguns estudos (e.g., BERENSON; OLDHAM; PRICE; LEITE, 2013; LIVY; VALE, 2011) mostram que eles sentem dificuldades neste conceito.

Assim, face às considerações anteriores, desenvolveu-se uma investigação com o objetivo de estudar o conhecimento de alunos, futuros professores dos primeiros anos de escolaridade, sobre o conceito de razão, nomeadamente ao nível da definição do conceito, das suas representações e das suas aplicações e conexões, a fim de obter dados que permitam intervir, fundamentadamente, na formação desses futuros educadores e professores, no que diz respeito à promoção do desenvolvimento do conceito em causa. Como defende Kind (2009), tornar este tipo de conhecimento mais explícito na formação inicial de docentes pode auxiliar os professores principiantes a desenvolverem as competências necessárias para se tornarem profissionais, ajudando-os a ajustar melhor o ensino aos contextos em que venham a 
lecionar. Conhecê-lo ajudará também os formadores desses educadores e professores a encontrar as melhores formas de promover o estabelecimento de ligações pedagógicas (SCOTT; MORTIMER; AMETLLERA, 2011) durante o processo de ensino e aprendizagem do conceito de razão e, em nossa opinião, também durante a abordagem da sua didática.

Para Scott, Mortimer e Ametllera (2011), o processo de aprendizagem de um conhecimento concetual é um processo de estabelecimento de ligações cujo sucesso depende daquelas que forem estabelecidas pelo estudante. O desafio que se coloca ao educador ou ao professor ou ao formador destes, é o de ajudar os seus estudantes a analisar as relações que estabelecem e/ou que promovem. Para estes autores, há três formas de estabelecer ligações pedagógicas: apoiar a construção de conhecimento, o que envolve a interligação de diversos tipos de conhecimento (por exemplo, entre explicações do dia a dia e explicações científicas e entre diversas formas de representação), para fomentar o desenvolvimento de compreensões profundas por parte dos estudantes; promover a continuidade, que assenta na ideia que aprendizagens profundas requerem que o ensino e a aprendizagem ocorram ao longo de um período considerável de tempo, durante o qual se estabelecem ligações entre o estudante e atividades de aprendizagem realizadas; encorajar o envolvimento emocional dos estudantes (por exemplo, trabalhando com as suas ideias, solicitando-lhes previsões), para obter uma resposta positiva por parte destes face ao processo de ensino e aprendizagem em curso.

\section{Fundamentação teórica}

\subsection{O conhecimento do professor para ensinar}

Determinar o conhecimento que o professor deve possuir para poder exercer a sua tarefa de ensinar encontra-se no centro das preocupações da investigação educacional. Schulman (1986) foi um dos primeiros investigadores a expressar a complexidade deste conhecimento, distinguindo três grandes categorias: o conhecimento do conteúdo, que se refere ao conhecimento do que se vai ensinar; o conhecimento pedagógico do conteúdo, relativo às formas como o professor representa e formula o seu conhecimento do conteúdo quando ensina; e o conhecimento do currículo, que se refere ao conhecimento relativo aos programas escolares, aos materiais de ensino e às indicações neles existentes.

Tendo por referência o trabalho de Schulman (1986), no caso da Matemática, Hill, Ball e Schilling (2008) distinguem duas grandes categorias de conhecimento relevantes para os professores: o conhecimento matemático e o conhecimento pedagógico do conteúdo. $\mathrm{Na}$ 
primeira categoria inclui-se o conhecimento comum do conteúdo, que se refere ao conhecimento que um adulto mobiliza para resolver problemas matemáticos; o conhecimento especializado do conteúdo, que diz respeito ao conhecimento especial do professor que o habilita a planificar e desenvolver sequências de ensino; e o conhecimento no horizonte matemático, que se refere aos aspetos mais avançados, como aspetos históricos e filosóficos, que proporciona perspetivas ao professor. Na segunda categoria inclui-se o conhecimento do conteúdo e os estudantes, que é relativo ao conhecimento sobre como os estudantes pensam, concetualizam ou aprendem um conteúdo; o conhecimento do conteúdo e o ensino, que é o conhecimento que resulta da integração do conhecimento do conteúdo matemático com o conhecimento sobre o ensino desse conteúdo; e o conhecimento do currículo, que se refere ao conhecimento das diretrizes curriculares, orientações, fins e motivações das mesmas, materiais curriculares e sequencialização do tema nos diferentes níveis escolares. O conhecimento pedagógico do conteúdo relativo a um tema matemático é mais do que o conhecimento resultante da simples prática profissional do professor. Diferentemente, ele resulta de investigação numa área de interseção entre o conhecimento matemático e o conhecimento educacional geral e tem como finalidade contribuir para melhorar a aprendizagem do conteúdo em causa (KANSANEN, 2009).

Integrando e ampliando os modelos anteriores, Godino (2009) e Godino, Batanero e Font (2007) propõem várias dimensões para analisar os processos de ensino e aprendizagem da Matemática: epistémica, que se refere aos conhecimentos matemáticos relativos ao contexto institucional em que se realiza o processo de aprendizagem (problemas, linguagens, procedimentos, definições, propriedades e argumentos); cognitiva, relativa aos conhecimentos pessoais dos estudantes e à progressão das aprendizagens; afetiva, que diz respeito aos estados afetivos (atitudes, emoções, crenças, valores) de cada aluno em relação aos objetos matemáticos e ao processo de estudo seguido; mediacional, relativa aos recursos tecnológicos e à atribuição do tempo às distintas ações e processos; interacional, referente aos padrões de interação entre o professor e os alunos e sua sequencialização orientada para a fixação e negociação de significados; e ecológica, em que se enfatiza o sistema de relações com o contexto social, político e económico.

No presente estudo estão especialmente envolvidas as dimensões epistémica, cognitiva e ecológica, no último caso enfatizando, sobretudo, as aplicações e conexões do conceito de razão. 


\subsection{0 conceito de razão}

Segundo Livy e Vale (2011), a "razão é a comparação entre duas quantidades" (p. 26). O conceito de razão é um conceito multifacetado e que se relaciona com muitos outros conteúdos matemáticos como, por exemplo, número racional, proporcionalidade e semelhança. Consequentemente, trata-se de um conceito usado em todas as principais áreas da Matemática, designadamente em números e álgebra, em probabilidades e estatística e em geometria.

No caso das diferentes interpretações de número racional, Lamon (2007) salienta que o conceito de razão mantém conexões com essas interpretações, incluindo mesmo a razão num dos seus constructos. De facto, a interpretação parte-todo tem fortes conexões com as interpretações de medida, razão e operador, o que facilita o desenvolvimento da noção de unidade de medida e de frações equivalentes e, em consequência, das operações de adição e de subtração. A interpretação de quociente mantém conexões naturais com razões e taxas, permitindo aos alunos usar com facilidade frações equivalentes, comparar frações e adicionar e subtrair frações. Já a interpretação de operador constitui um contexto útil para a multiplicação e divisão de frações. Por sua vez, a interpretação de medida facilita o desenvolvimento das noções de unidade, equivalência, ordem e densidade dos números racionais e das operações de adição e subtração. Embora as interpretações, anteriormente referidas, sejam concetualmente diferentes, elas são indistinguíveis quando são escritas simbolicamente, pelo que as operações de adição, subtração, multiplicação e divisão, apesar de diferentes, regem-se pelas mesmas regras. Já no caso da interpretação de razão não operamos com razões da mesma forma que operamos com frações.

Segundo Suggate, Davis e Goulding (2006), existem três principais tipos de comparações de razões: parte-parte (por exemplo, o José comeu duas partes do bolo e a Maria comeu três partes); parte-todo (por exemplo, o José comeu duas das cinco partes do bolo); e todo-todo (por exemplo, $1 \mathrm{~cm}$ no mapa corresponde a $1000000 \mathrm{~cm}$ no terreno). Para Livy e Vale (2011), "a linguagem e a variedade de situações de razão podem ser motivo de confusão quando se trabalha com situações de razão" (p. 26). Essa confusão pode ser reforçada pelo facto de os manuais escolares adotarem diferentes abordagens e sequências concetuais e de selecionarem aplicações com características diferentes, por vezes centradas unicamente no conceito específico em causa (LO; CAI; WATANABE, 2001). Por isso, Beswick (2011) defende que um aspeto chave quando se ensina acerca de razão consiste em 
ajudar os estudantes a conhecerem e a relacionarem as diferentes representações da mesma, designadamente em contextos reais. No entanto, o sucesso alcançado pelos estudantes depende do tipo de problema com que são confrontados (SINGH, 2000), mesmo quando se recorre a estratégias especificamente desenhadas para fomentar o domínio deste conceito, incluindo interligação concetual e diversidade de representações (JITENDRA ET AL., 2009).

Tal como os alunos, também os professores dos primeiros anos de escolaridade revelam limitações no conhecimento do conteúdo matemático, ao verificar-se que são bem-sucedidos na realização de cálculos, mas incapazes de mostrarem uma compreensão concetual em diversos tópicos matemáticos, salientando-se o de não reconhecerem a diferença entre frações e razões e o raciocínio proporcional (LIVY; VALE, 2011). Ora, esta falta de conhecimento matemático é também consequência de, frequentemente, a formação inicial destes professores não incluir o estudo do conceito de razão, centrando-se antes em outras áreas de conhecimento dos números.

Também Berenson et al. (2013) examinaram as conceções e as representações de futuros professores do Ensino Primário e de Matemática e de Ciências do Ensino Secundário para determinar o seu conhecimento para o ensino do conceito de razão. Em termos de significado, muitos alunos definiram a razão como comparação/relação ou como fração/percentagem/proporção/divisão. Já em termos de representações através de símbolos matemáticos, os alunos usaram os dois pontos (:), isoladamente ou em expressões do tipo: $x: y$ ou $3: 2$, e frações; enquanto nas representações de como as razões são usadas, os alunos fizeram desenhos, diagramas e outras representações pictóricas, refletindo comparações ou representações numéricas (usualmente em contextos do dia a dia), propriedades geométricas (por exemplo, a semelhança) ou apresentações estatísticas (gráfico de barras); e poucos alunos apresentaram desenhos que ilustravam aplicações de razão (escalas de mapas, culinária, arquitetura e design). Finalmente, outros alunos apresentaram representações numéricas, algébricas ou verbais, semelhantes às representações vistas antes em termos de símbolos matemáticos.

Chick (2010) constatou que embora professores de Matemática consigam reconhecer as conceções alternativas que os alunos perfilham sobre o conceito de razão, eles não conseguem gerar exemplos considerados adequados para ajudar os alunos a alterá-las. Já Ilany, Keret e Bem-Chaim (2004) constataram que o uso de atividades de investigação envolvendo tarefas familiares aos futuros professores de Matemática e que requerem o uso e relacionamento de 
diversos conceitos implicados na noção de razão podem ajudar a melhorar, não só o seu conhecimento concetual, mas também o seu conhecimento pedagógico do conteúdo. Assim, parece necessário conhecer as dificuldades concetuais e metodológicas dos futuros educadores e professores dos primeiros anos de escolaridade relacionadas com o conceito de razão para, a partir delas, organizar estratégias formativas que lhes permitam desenvolver a sua própria compreensão concetual do conceito de razão, bem como estratégias adequadas para o ensinarem aos seus futuros alunos.

\section{Metodologia}

O presente estudo centra-se na análise da compreensão do conceito de razão por estudantes do ensino superior de uma universidade do norte de Portugal, futuros educadores e professores dos primeiros anos de escolaridade, incluindo os seus significados, as suas ideias acerca do uso deste conceito, por si próprios e por outrem, e as suas representações. Assim, e como referimos anteriormente, o objetivo do estudo consistiu em estudar as conceções e as representações destes futuros educadores de infância e professores dos seis primeiros anos de escolaridade acerca do conceito matemático de razão.

Participaram no estudo 81 estudantes do $2^{\circ}$ ano do curso de Licenciatura em Educação Básica de uma universidade do norte de Portugal, curso que dá acesso a mestrados profissionalizantes para exercício de atividade docente na Educação Pré-Escolar e no $1^{\circ}$ Ciclo (correspondente aos primeiros quatro anos de escolaridade) e $2^{\circ}$ Ciclo (correspondente ao $5^{\circ}$ e $6^{\circ}$ anos de escolaridade) do Ensino Básico, designadamente Mestrado em Educação PréEscolar, em Educação Pré-Escolar e Ensino do $1^{\circ}$ Ciclo do Ensino Básico e em Ensino do $1^{\circ}$ e $2^{\circ}$ Ciclos do Ensino Básico.

Estes estudantes possuíam uma formação em Matemática muito variada, o que era consequência, sobretudo, do nível de abordagem com que essa disciplina é tratada nos diferentes cursos que frequentaram antes da entrada no curso universitário. Além disso, estes alunos não tinham estudado formalmente o conceito de razão no curso universitário nem tinham qualquer experiência de ensino.

A recolha dos dados foi efetuada através de um questionário, aplicado numa das aulas dos estudantes, composto por várias questões sobre o conceito de razão, e que constam da Figura 1. 
1. O que significa para ti, o termo "razão"?

2a. Em que situações usas razões?

2b. Que outras pessoas mais usam razões e em que situações o fazem?

3. Como representas uma razão, usando símbolos matemáticos?

Se for relevante, indica qual ou quais os principais símbolos que utilizas para o efeito, listando também os outros que conheças.

Podes escrever expressões que incluam os símbolos, em vez de escrever apenas os símbolos e continuar no verso da folha, se for necessário.

4. Que representações (desenhos, mapas, gráficos, palavras, entre outros) poderias usar para explicar o conceito de razão e para mostrar como ele é utilizado? Dá exemplos que ilustrem as tuas propostas. Podes continuar no verso da folha, se for necessário.

Figura 1 - Questões incluídas no questionário

Fonte: Adaptado de Berenson et al. (2013).

Como se pode verificar, todas as questões são de resposta aberta e organizam-se em torno de quatro dimensões, sendo a primeira dirigida ao significado do termo razão, as duas seguintes centram-se nos usos do conceito de razão e as duas últimas, respetivamente, nas representações simbólicas do conceito e nas representações para explicação do conceito.

Em termos de tratamento e análise de dados, recorremos à análise de conteúdo, cujas categorias, emergentes das respostas apresentadas pelos estudantes, são descritas na próxima secção, quando da apresentação de resultados, tendo-se também determinado frequências e usado tabelas para resumir a informação. A categorização efetuada será ilustrada com exemplos ou extratos de respostas, cuja origem será identificada pela letra E, de estudante, seguido de um algarismo correspondente ao número de ordem atribuído ao mesmo.

\section{Apresentação de resultados}

Nesta secção serão apresentados os resultados obtidos, em quatro subsecções, cada uma delas centrada numa dimensão da investigação: significado de razão; usos do conceito de razão; representação simbólica de razão; e representação para explicação do conceito de razão.

\subsection{Significado de razão}

Quando questionados sobre o significado de razão, os estudantes inquiridos apresentaram uma diversidade de significados, que constam da Tabela 1, embora cada estudante tenha apresentado apenas um significado.

Tabela 1 - Diferentes significados atribuídos ao conceito razão $(n=81)$ 


\begin{tabular}{lc}
\hline Significado & N. $^{\text {de de estudantes }(\%)}$ \\
\hline Comparação/relação & $41(51)$ \\
Operação matemática & $14(17)$ \\
Proporção & $7(9)$ \\
Número racional & $1(1)$ \\
Fração & $4(5)$ \\
Incompreensíveis & $10(12)$ \\
Não respostas & $4(5)$ \\
\hline
\end{tabular}

Fonte: Elaboração dos autores.

De entre os diferentes significados atribuídos ao termo razão, salienta-se que cerca de metade $(51 \%)$ identificaram a razão com uma comparação/relação entre grandezas (Tabela 1), sendo que as respostas de $68 \%$ desses estudantes foram mais específicas, referindo que essa comparação/relação envolve duas grandezas. Esta ideia é ilustrada pela resposta do estudante E1, apresentada na Figura 2.

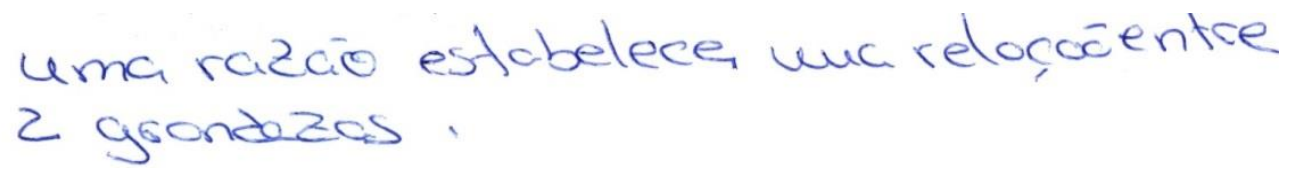

Figura 2 - Significado de razão do estudante E1

Seguiu-se, em termos de percentagem, a ideia de razão como operação matemática, com $17 \%$ de respostas (Tabela 1). Na maioria dos casos, as operações mencionadas foram a multiplicação ou a divisão, como é ilustrado na Figura 3.

\section{Razão significa diviscio.}

Figura 3 - Significado de razão do estudante E20

Contudo, 29\% desses estudantes atribuiu ao termo razão o significado de operação de adição ou de subtração, o que corresponde a um significado errado da ideia de razão. No caso da resposta dada pelo estudante E29 (Figura 4), verifica-se que, para além da identificação da razão com a operação de subtração, ele admite que o conceito de razão poderá envolver mais do que dois termos.

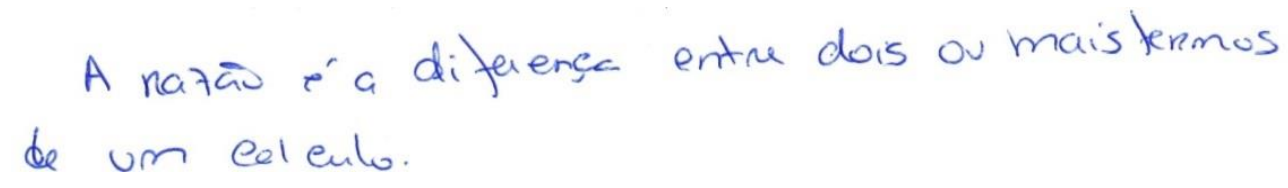

Figura 4 - Significado de razão do estudante E29 
Finalmente, e embora em pequenas percentagens (Tabela 1), alguns estudantes atribuíram ao termo razão o significado de proporção $(9 \%)$, fração $(5 \%)$ e número racional (1\%). O primeiro destes significados pode ser ilustrado pela resposta do estudante E42, apresentada na Figura 5. Embora sem serem coincidentes, o significado de proporção está relacionado com o significado de razão, pois uma proporção envolve uma igualde entre duas razões.

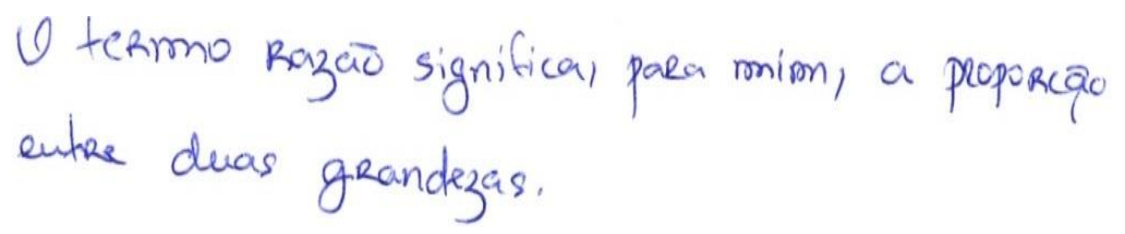

Figura 5 - Significado de razão do estudante E42

Observaram-se, ainda, algumas (5\%) não respostas e situações (12\%) em que não foi possível categorizar as respostas dos estudantes em virtude da sua não inteligibilidade, tendo as mesmas sido incluídas na categoria incompreensíveis.

Em síntese, salienta-se a definição de razão como razão/relação entre (duas) grandezas, tal como a estabelece Livy e Vale (2011), traduzindo coincidência entre as dimensões cognitiva e epistémica (GODINO, 2009). Já na dimensão cognitiva, sem coincidência com a dimensão epistémica, destacam-se as dificuldades explícitas dos estudantes ao identificarem a razão com as operações de adição e subtração de grandezas e implícitas ao não responderem e ao apresentarem respostas incompreensíveis.

\subsection{Usos do conceito de razão}

Quando os estudantes foram questionados sobre as situações em que usam as razões, constatou-se que a maioria das suas respostas (78\%) centra-se em contextos académicos (Tabela 2).

Tabela 2 - Situações em que os estudantes afirmam usar o conceito de razão $(n=81)$

\begin{tabular}{lc}
\hline Situações de uso & N. $^{\text {o de estudantes }(\%)}$ \\
\hline Contexto académico & $63(78)$ \\
Contexto quotidiano & $25(31)$ \\
Medição de quantidades & $4(6)$ \\
Incompreensíveis & $1(1)$ \\
Não respostas & $3(4)$ \\
\hline
\end{tabular}

Fonte: Elaboração dos autores. 
Dentro desta categoria foram indicadas várias situações, em que o conceito matemático de razão surge associado ao contexto escolar. Especificamente, os estudantes referem-se a fazer uso do conceito de razão em:

- situações da disciplina de Matemática, em geral (38\%), não sendo especificado o contexto ou finalidade com que isso ocorre;

- áreas ou conceitos específicos da Matemática, designadamente na área das Probabilidades (2\%), nas proporções (10\%), na comparação ou estabelecimento de relações matemáticas (26\%), em operações matemáticas de divisão ou multiplicação (9\%), na determinação de grandezas (10\%) e na representação de dados em gráficos e tabelas $(7 \%)$;

- outras áreas científicas, nomeadamente na Física e Química (11\%) e nas Artes (19\%); na primeira referem o uso do conceito de razão no cálculo de velocidades ou na determinação de densidades de diversas substâncias, enquanto na segunda, aludem ao seu uso no cálculo de escalas, nas homotetias ou no desenho.

A categoria seguinte, o uso do conceito de razão em contextos do quotidiano, foi indicada por cerca de um terço (31\%) dos estudantes (Tabela 2). Muitos destes estudantes não especificaram as situações de uso em contextos do quotidiano (76\%), mas outros explicitaram essas situações, mencionando, designadamente: situações de compra e venda de produtos envolvendo o cálculo de percentagens (16\%); situações de culinária (8\%); e situações de agricultura (8\%).

Finalmente, os $6 \%$ dos estudantes cujas respostas foram incluídas na categoria medição de quantidades (Tabela 2) afirmaram utilizar o conceito matemático de razão no ato de medir.

Observou-se, ainda, uma resposta que não foi possível categorizar, em virtude da sua não inteligibilidade, a qual foi incluída na categoria incompreensíveis, e algumas (4\%) não respostas.

Na Tabela 3 encontram-se registados os resultados obtidos quando os estudantes foram questionados relativamente a situações de uso do conceito matemático de razão por outras pessoas, que não eles próprios. Note-se que alguns estudantes apresentaram mais do que uma situação. 
Tabela 3 - Situações em que os estudantes afirmam que outras pessoas usam o

\begin{tabular}{lc}
\multicolumn{2}{c}{ conceito de razão $(\mathrm{n}=81)$} \\
\hline Área & N. $^{\text {o de estudantes }(\%)}$ \\
\hline Matemática & $21(26)$ \\
Ciências & $20(25)$ \\
Pessoas em geral & $13(16)$ \\
Ciências Humanas e Sociais & $10(12)$ \\
Negócios & $9(11)$ \\
Trabalhadores qualificados e não qualificados & $6(7)$ \\
Tecnologias & $4(5)$ \\
Desporto & $3(4)$ \\
Direito & $2(2)$ \\
Incompreensíveis & $5(6)$ \\
Não respostas & $18(22)$ \\
\hline
\end{tabular}

Fonte: Elaboração dos autores.

Da análise da Tabela 3, constata-se que, de entre as diferentes áreas mencionadas pelos estudantes, as ligadas à Matemática (26\%) e às Ciências (25\%) foram as referidas por um maior número (cerca de um quarto) de estudantes. No caso de situações ligadas à área da Matemática foram indicados profissionais tais como professores de Matemática (2\%), profissionais ligados à Estatística e/ou Probabilidades (9\%) e matemáticos em geral (15\%). Neste caso observa-se uma grande discrepância entre a incidência do uso do conceito de razão, consoante os alunos se referem a si próprios ou às outras pessoas, muito inferior neste último caso. No caso das situações de uso no âmbito das Ciências (Física e Química), os estudantes reportam-se aos casos dos engenheiros físicos e/ou químicos (12\%), dos investigadores $(12 \%)$ e dos professores $(1 \%)$.

Um número considerável de estudantes (16\%) indica que o conceito de razão é usado pelas pessoas em geral (Tabela 3), referindo-se, provavelmente, ao uso do conceito razão como sendo independente da situação profissional que a pessoa possa ter.

$\mathrm{Na}$ categoria seguinte, em termos percentuais, ciências humanas e sociais (12\%), observou-se que os respetivos estudantes indicaram profissões como geógrafos $(6 \%)$, sociólogos (3\%), filósofos (1\%), políticos (1\%) ou psicossociólogos (1\%).

$\mathrm{Na}$ categoria negócios, com cerca $11 \%$ de respostas, os estudantes mencionaram profissionais tais como contabilistas $(4 \%)$, bancários $(4 \%)$, economistas $(2 \%)$ ou comerciantes $(1 \%)$.

As restantes áreas de atividade registaram percentagens inferiores a 10\% (Tabela 3) e incluem: 
- trabalhadores qualificados e não qualificados (7\%), tendo sido indicadas pessoas cuja ocupação se refere a funcionário de supermercado, pasteleiro, padeiro ou funcionário da construção civil;

- tecnologias (5\%), tendo sido mencionados profissionais de áreas mais técnicas, tais como engenheiros ou informáticos;

- desporto (3\%), tendo sido referidos profissionais ligados à área do desporto, em geral, ou situações particulares, como personal trainers;

- direito (2\%), tendo sido mencionados profissionais como juízes e advogados.

Nesta questão verificou-se um elevado número de estudantes (22\%) que não apresentou qualquer resposta e algumas respostas $(6 \%)$ que se revelaram incompreensíveis.

Para os estudantes, as aplicações e conexões do conceito de razão, que se inserem na dimensão ecológica (GODINO, 2009), são diversificadas e a maior incidência nas situações académicas, quando os estudantes se referem a si próprios, terá certamente origem nas suas próprias experiências escolares.

\subsection{Representação simbólica de razão}

Na Tabela 4 apresentam-se os diferentes tipos de representações de razão indicadas pelos estudantes, quando lhes foi solicitado que representassem esse conceito recorrendo a símbolos matemáticos. Note-se que alguns estudantes apresentaram mais do que uma representação.

Tabela 4 - Tipos de representações simbólicas de uma razão referidas pelos estudantes $(\mathrm{n}=81)$

\begin{tabular}{lc}
\hline Tipos de representações simbólicas & N. $^{\circ}$ de estudantes $(\%)$ \\
\hline Operações com letras & $48(59)$ \\
Operações com constantes & $25(31)$ \\
Apenas sinais de operação & $11(14)$ \\
Relações & $5(6)$ \\
Percentagem & $1(1)$ \\
Outras representações & $8(10)$ \\
Não respostas & $5(6)$ \\
\hline
\end{tabular}

Fonte: Elaboração dos autores.

Pela Tabela 4 verifica-se que mais de metade dos estudantes apresentaram representações simbólicas (59\%) que se referem a operações com letras. Estas representações incluem algumas palavras e constituem representações, de natureza geral, envolvendo 
operações ou frações do tipo $a: b, \frac{a}{b}$ e $a / b$ (Figura 6). Particularmente nas duas últimas representações, os símbolos - e / podem referir-se tanto a uma fração como à operação de divisão.

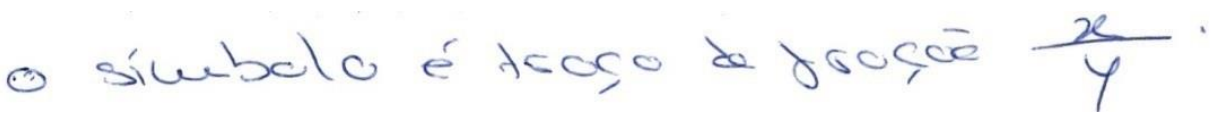

Figura 6 - Representação de razão do tipo operações com letras pelo estudante E1

A Tabela 4 mostra ainda que cerca de um terço dos estudantes (31\%) apresentaram representações do tipo operações com constantes. Estas representações, de natureza específica, são semelhantes na forma às representações do tipo anterior, de natureza geral, quando os estudantes substituem as letras por números na respetiva operação de divisão (Figura 7), adição ou subtração. No caso da operação de adição e subtração (três representações) corrobora-se o significado errado antes atribuído por alguns alunos ao conceito de razão.

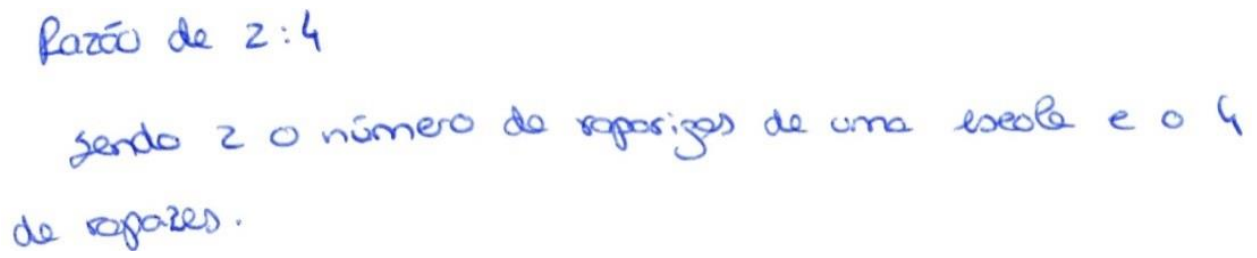

Figura 7 - Representação de razão do tipo operações com constantes pelo estudante E6

No caso do recurso apenas sinais de operação (14\%), os estudantes referiram somente símbolos das operações de divisão (quatro representações), de multiplicação (uma representação), de subtração (três representações) e de adição (uma representação).

Os restantes tipos de representações foram efetuados por percentagens de estudantes iguais ou inferiores a 10\% (Tabela 4) e incluem os seguintes:

- relações (6\%), tendo os estudantes mencionado relações de igualdade (=) e de desigualdade $(<$ ou $>$ ), em alguns casos envolvendo letras (duas representações) e em outros apenas os símbolos das relações (três representações);

- percentagem (1\%), tendo o único aluno escrito apenas uma percentagem;

- outras representações que incluem símbolos que não são muito usuais, como por exemplo: $r \mathrm{e} \rightarrow$. No caso do símbolo $r$ é possível que a sua seleção pelos estudantes esteja associada ao uso deste símbolo na representação de razão das relações de proporcionalidade direta. 
Nesta questão, e como se pode constatar pela Tabela 4, verificou-se um reduzido número de não respostas (6\%) e não se obtiveram respostas incompreensíveis.

Em síntese, em termos de formas de representação mais adequadas, destaca-se que cerca de $76 \%$ das representações referidas pelos estudantes incluem os símbolos : ou /, seja de forma isolada ou envolvendo letras ou números. Estas representações simbólicas do conceito de razão também foram observadas por Berenson et al. (2013) em futuros professores, verificando-se, para a maioria dos estudantes, existir coincidência entre as dimensões cognitiva e epistémica e envolver a interpretação de quociente de números racionais, de acordo com uma das interpretações de número racional proposta por Lamon (2007). Adicionalmente, nos casos das outras representações referidas pelos estudantes, elas são pouco frequentes e explicitam ou indiciam discrepâncias entre as duas dimensões, a epistémica e a cognitiva, o que corresponde a dificuldades e erros dos estudantes.

\subsection{Representação para explicação do conceito de razão}

$\mathrm{Na}$ última questão foi pedido aos estudantes que indicassem formas de representação que eles utilizariam para explicar o conceito razão. Também neste caso alguns estudantes apresentaram mais do que uma representação.

Tabela 5 - Tipos de representações que os estudantes usariam para explicar o conceito de razão $(n=81)$

\begin{tabular}{lc}
\hline Tipos de Representações & N. $^{\text {o de estudantes }(\%)}$ \\
\hline Diagramas ou representações gráficas & $34(42)$ \\
Símbolo matemático & $16(20)$ \\
Escalas & $8(10)$ \\
Tabelas & $5(6)$ \\
Cálculos & $5(6)$ \\
Palavras & $2(2)$ \\
Incompreensíveis & $4(5)$ \\
Não respostas & $14(17)$ \\
\hline
\end{tabular}

Fonte: Elaboração dos autores.

Da análise dos dados apresentados na Tabela 5, verifica-se que diagramas ou representações gráficas foi o tipo de representação a que maior número de estudantes (42\%) recorreria. Este tipo geral de representação abrange uma diversidade de representações específicas que diferem em alguns aspetos e que explicitamos em seguida. Assim, alguns estudantes: 
- efetuaram apenas o desenho do diagrama/gráfico, enquanto outros optaram por construir o diagrama/gráfico e definir a fração correspondente. Por exemplo, o estudante E18 recorreu a um diagrama de área e a um gráfico circular para estabelecer uma relação parte-todo (Figura 8);

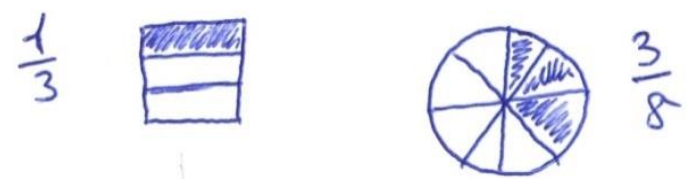

Figura 8 - Representação de razão através de diagramas de área e frações pelo estudante E18

- usaram diagramas discretos para estabelecer uma relação parte-todo, acompanhados, ou não, da respetiva fração. O estudante E41 usou um diagrama discreto e explicitou a respectiva fração (Figura 9);

\section{$000=$ A razào de ćŕrulos pintados é $\frac{3}{5} \frac{1}{3}$.}

Figura 9 - Representação de razão através de diagrama discreto e fração pelo estudante E41

- recorreram a outras formas de representação gráfica, tais como outros tipos de desenhos. Assim, o estudante E41 desenhou dois triângulos semelhantes e estabeleceu a razão entre eles, talvez entre os perímetros ou os comprimentos dos lados (Figura 10), enquanto o estudante E35 usou a imagem pictórica de uma pessoa para representar a razão, enfatizando uma relação do tipo todo-todo (Figura 11).

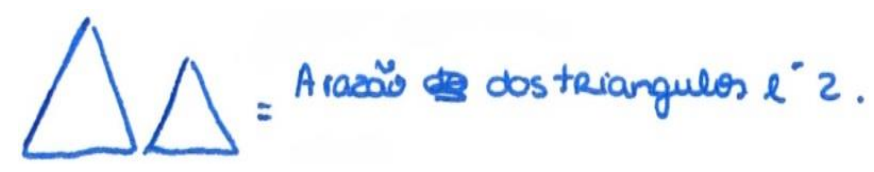

Figura 10 - Representação de razão através de um desenho pelo estudante E41

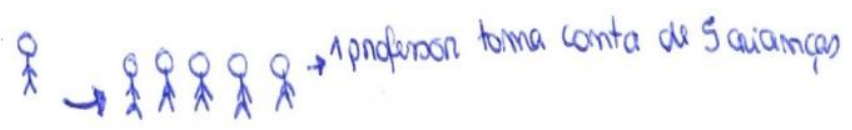

Figura 11 - Representação de razão através de um desenho pelo estudante E35

Ainda com base na Tabela 5 constata-se que um quinto dos estudantes recorreria a representações que incluem apenas um símbolo matemático (20\%) para representar uma razão quando da explicação deste conceito. As suas respostas mencionavam apenas o símbolo matemático (que, na maioria das vezes, era o símbolo da operação de divisão ou de multiplicação), não acrescentando mais informação. 
As restantes categorias foram apresentadas por um número de estudantes igual ou inferior a dez por cento e destacam características muito variadas. Assim, alguns estudantes forneceram representações do tipo:

- escalas (10\%), sendo que estes estudantes recorreram à escala de um mapa para explicar o conceito de razão. Alguns destes alunos referem apenas a situação sem acrescentar qualquer informação de como a utilizar na explicação, enquanto outros explicam como utilizariam a situação, indicando a forma de calcular a razão (Figura 12);

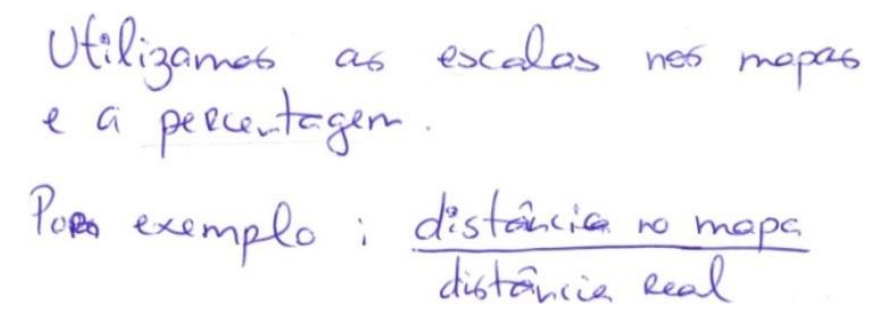

Figura 12 - Representação do conceito de razão com recurso à noção de escala pelo estudante E61

- tabelas (6\%), sendo que, também nesta categoria, se observou que alguns estudantes apenas indicaram esta forma de organização de informação sem qualquer outra explicação, enquanto outros construíram tabelas com dados e explicitaram o conceito matemático de razão (Figura 13). Observa-se que, neste caso, o estudante E12 associa a conceito de razão à constante de uma proporcionalidade direta.

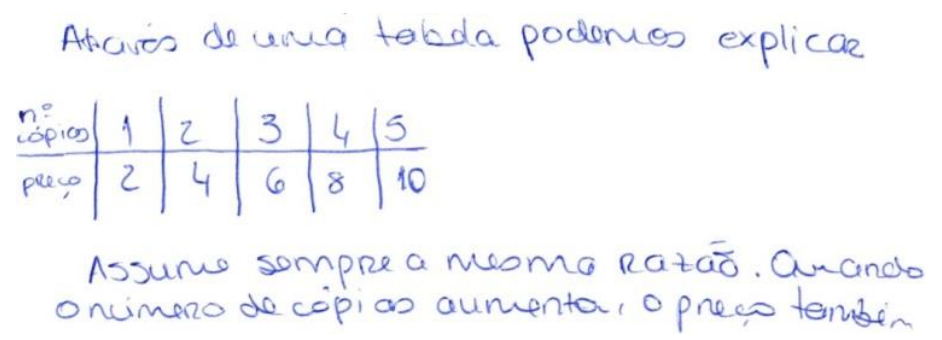

Figura 13 - Representação do conceito de razão através de uma tabela pelo estudante E12

- cálculos (6\%), sendo que nesta categoria se incluíram os alunos que referiram apenas cálculos, sem indicar que tipo de cálculos utilizariam ou a forma como o fariam na tentativa de explicar o conceito matemático de razão;

- palavras $(2 \%)$, onde se incluíram as respostas que explicam o conceito matemático de razão recorrendo a um exemplo concreto e explicando-o através de palavras e, em alguns casos, também de símbolos matemáticos (Figura 14). 


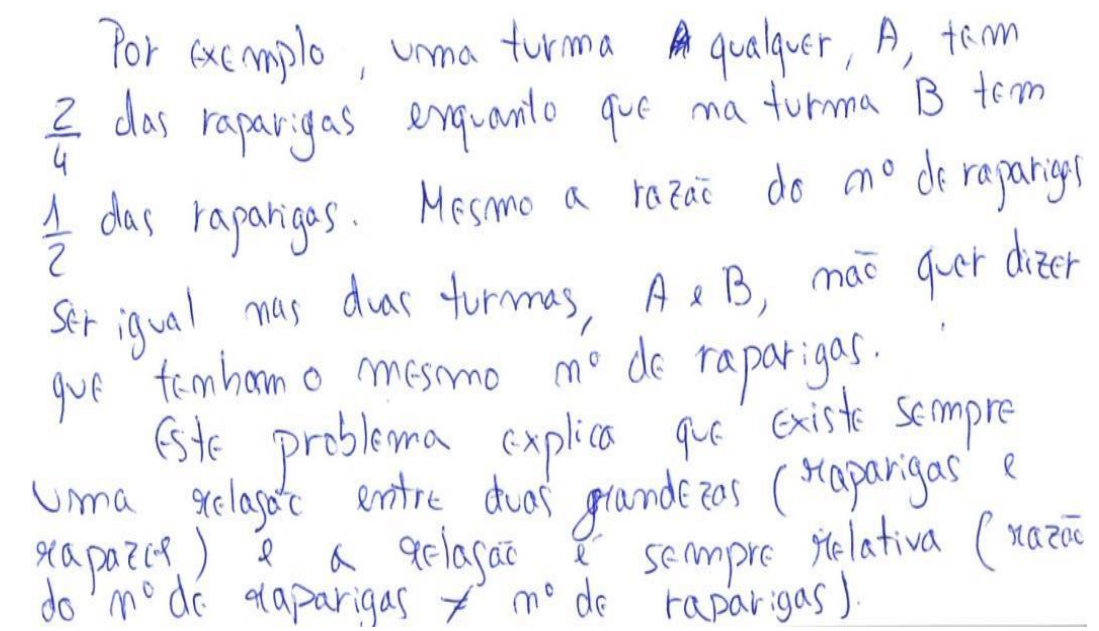

Figura 14 - Representação do conceito de razão por palavras e símbolos pelo estudante E17

Finalmente, note-se que nesta questão observou-se um elevado número de alunos que não responderam $(17 \%)$ e, embora em menor número (5\%), alguns alunos apresentaram respostas incompreensíveis.

Nesta questão, focada nas dimensões epistémica e cognitiva, face à solicitação de explicar o conceito de razão a outrem, os estudantes apresentaram representações mais explicativas, o que contrasta com as representações muito sintéticas indicadas pelos estudantes na questão anterior. Esse caráter mais explicativo resultou do uso de diagramas, gráficos, desenhos e tabelas, como também referem Berenson et al. (2013), e revela, ao nível da dimensão cognitiva, uma perspetiva mais profunda do conceito de razão. Por outro lado, nestas representações, ainda que não explicitadas, observam-se relações do tipo todo-todo e parte-todo, esta última referida por Lamon (2007) como uma das interpretações de número racional.

\section{Discussão e conclusão}

A discussão dos resultados será efetuada com base nas dimensões de análise do processo de ensino e aprendizagem da Matemática propostas por Godino (2009). Como referimos anteriormente, dessas dimensões destacam-se no presente estudo as dimensões epistémica, cognitiva e ecológica. Quer na dimensão epistémica, a qual tem a ver com o conhecimento matemático institucional, quer na dimensão cognitiva, que se refere aos conhecimentos pessoais dos estudantes e à sua progressão na aprendizagem, intervém o conhecimento dos diferentes tipos de objetos matemáticos, tais como situações-problema, representações, definições, argumentos, etc., salientando-se no estudo realizado os objetos 
matemáticos definição do conceito e representações a ele associadas.

Enquanto fim último da aprendizagem dos estudantes, pretende-se que a dimensão cognitiva coincida com a dimensão epistémica. Neste caso, segundo os dados apresentados na Tabela 1, para cerca de dois estudantes em cada três, o conceito de razão significa ou comparação/relação entre grandezas ou uma operação matemática. No entanto, tal como constaram Suggate, Davis e Goulding (2006), verificou-se a ausência de qualquer especificação do tipo de comparação envolvida. Além disso, são poucos os alunos que especificam as operações de divisão e multiplicação que, segundo Lamon (2007), estão associadas ao conceito de razão e ao conceito de número racional. Constata-se assim, que as definições dadas pelos futuros professores apresentam uma débil conexão entre o conceito de razão e o conceito de número racional, pois apenas uma resposta foi considerada como estabelecendo essa relação.

No que se refere às representações, como evidencia a Tabela 4, quando usam símbolos matemáticos para representar o conceito, a grande maioria dos estudantes recorre a operações com letras, a operações com constantes ou apenas a sinais de operação. Já as representações dos estudantes, tendo em vista explicar o conceito de razão a outrem (Tabela 5), são mais esclarecedoras do que as que usam para apoiar a sua definição. Na verdade, embora alguns estudantes continuem a recorrer a símbolos matemáticos como recorreram no caso anterior, neste caso, o recurso a diagramas ou representações gráficas foi o tipo de representação mais usado. Embora sem o referirem explicitamente, em alguns diagramas e gráficos, os estudantes recorrem a comparações do tipo parte-todo e todo-todo para explicarem o conceito a outrem.

É ainda de realçar a abrangência que o conceito de razão tem para os inquiridos, conforme é patente nas respostas dadas pelos estudantes (Tabela 1), bem como as dificuldades e limitações concetuais reveladas explícita e implicitamente nas suas respostas. Sobretudo em relação ao significado do conceito de razão, as respostas, muito curtas, apresentadas pelos estudantes tornam-nas pouco explicativas e, tal como foi referido antes, com ténues conexões com as várias interpretações de número racional e sem especificar o tipo de comparação envolvida. Embora esta situação tenha melhorado quando foi pedido aos estudantes que descrevessem como explicariam o conceito a outrem, verifica-se, ainda assim, uma considerável percentagem de estudantes que não apresentaram respostas compreensíveis ou que não apresentaram qualquer resposta (Tabela 5).

Em termos de dificuldades concetuais, destaca-se, quer ao nível da definição do 
conceito quer da sua representação, em alguns estudantes, a alusão às operações de adição e de subtração, o que traduz uma ideia errada do conceito de razão.

Em geral, no que diz respeito ao significado e às representações do conceito de razão, os resultados do presente estudo são concordantes com os que foram obtidos por Berenson et al. (2013). Neste último estudo estiveram envolvidos futuros professores do Ensino Primário e do Ensino Secundário de diferentes países, o que implica que as dificuldades experimentadas pelos estudantes não constituem uma questão exclusiva do caso português.

Finalmente, na dimensão ecológica (Godino, 2009), referente às relações com o contexto social e político e económico, incluem-se os contextos de uso do conceito de razão, tendo-se obtido diferenças entre os usos pelos próprios estudantes (Tabela 2) e os usos por outras pessoas (Tabela 3). Em geral, os estudantes foram capazes de reconhecer usos diversificados do conceito de razão e entre os usos deles próprios e de outras pessoas, como seria de esperar, salientam-se, no primeiro caso, situações de uso de âmbito académico e, no segundo caso, situações de uso de âmbito das profissões.

No âmbito académico são predominantes situações relacionadas com a Matemática, enquanto no âmbito das profissões existe um quase equilíbrio entre as áreas de Ciências e de Matemática. Esta discrepância entre contextos de uso do conceito pode significar que os estudantes têm muito presente o estudo da Matemática no seu curso e que perspetivam menos oportunidades de uso da Matemática na vida futura.

A análise dos resultados obtidos com base nas três dimensões do processo de ensino e aprendizagem da Matemática - epistémica, cognitiva e ecológica (GODINO, 2009) - revelam um conhecimento matemático do conceito de razão, por parte dos estudantes, com algumas fragilidades, sobretudo ao nível da definição do conceito e das suas representações. Ora, na perspetiva destes estudantes virem a ser educadores ou professores dos primeiros anos de escolaridade, torna-se imprescindível que eles adquiram uma compreensão mais profunda do conceito de razão, designadamente através da exploração de uma ampla variedade de exemplos e da sua resolução recorrendo a mais do que um método, do uso de diferentes formas de representação, do estabelecimento de conexões com outros conceitos e da análise dos diferentes tipos de razão: parte-parte, parte-todo e todo-todo (LIVY; VALE, 2011). Só trabalhando o conceito de razão, explicitamente e com métodos apropriados aos estudantes e às exigências da sua futura profissão, será possível promover o desenvolvimento concetual dos futuros professores, quer ao nível do que Shulman (1986) designa de conhecimento do 
conteúdo, quer ao nível do que o mesmo autor designa por conhecimento pedagógico do conteúdo.

\section{Agradecimento}

Este trabalho contou com o apoio de Fundos Nacionais através da FCT - Fundação para a Ciência e a Tecnologia no âmbito do projecto PEst-OE/CED/UI1661/2014 do CIEd-UM.

\section{Referências}

BERENSON, S.; OLDHAM, E.; PRICE, E.; LEITE, L. Investigating representations of ratio among prospective mathematics and science teachers: an international study. In: ATEE CONFERENCE Teacher Education Policies and Professionalisation. $37^{\text {th }}$, 2012, Eskisehir. Proceedings... Bruxelas: ATEE, 2013. p. 78-92.

BESWICK, K. Make your own paint chart: a realistic context to develop proportional reasoning with ratios. Australian Mathematics Teacher, Adelaide, v. 67, n. 1, p. 6-11, Mar. 2011.

CHICK, $\mathrm{H}$. Aspects of teachers' knowledge for helping students learn about ratio. In: CONFERENCE OF THE MATHEMATICS EDUCATION RESEARCH GROUP OF AUSTRALASIA. $33^{\text {th }}, 2010$, Fremantle. Proceedings... Fremantle: MERGA, 2010, p. 145-152.

GODINO, J. D. Categorías de análisis de los conocimientos del profesor de matemáticas. UNIÓN Revista Iberoamericana de Educación Matemática, La Laguna, n. 20, p. 13-31, Dez. 2009.

GODINO, J. D.; BATANERO, C.; FONT, V. The onto-semiotic approach to research in mathematics education. ZDM - The International Journal on Mathematics Education, Dordrecht, v. 39, n. 1/2, p. 127-135. Jan. 2007.

HILL, H. C.; BALL, D. L.; SCHILLING, S. G. Unpacking pedagogical content knowledge: Conceptualizing and measuring teachers' topic-specific knowledge of students. Journal for Research in Mathematics Education, Virginia, v. 39, n. 4, p. 372-400, Jul. 2008.

ILANY, B.; KERET, Y.; BEM-CHAIM, D. Implementation of a model using authentic investigative activities for teaching ratio \& proportion in pre-service teacher education. In: CONFERENCE OF THE INTERNATIONAL GROUP FOR THE PSYCHOLOGY OF MATHEMATICS EDUCATION. $28^{\text {th }}$, 2004, Bergen. Proceedings... Bergen: PME, 2004. p. 81-88.

JITENDRA, A; STAR, J. R.; STAROSTA, K.; LEH, J. M.; SOOD, S.; CASKIE, G.; HUGHES, C. L.; MACK, T. R. Improving seventh grade students' learning of ratio and proportion: the role of schemabased instruction. Contemporary Educational Psychology, v. 34, n. 3, p. 250-264, Jul. 2009.

KANSANEN, P. Subject-matter didactics as a central knowledge base for teachers, or should it be called pedagogical content knowledge? Pedagogy, Culture \& Society, Londres, v. 17, n. 1, p. 29-39, Mar. 2009.

KIND, V. Pedagogical content knowledge in science education: perspectives and potential for progress. Studies in Science Education, Londres, v. 45, n. 2, p. 169-204, Aug. 2009. 
LAMON, S. J. Rational numbers and proportional reasoning : Toward a theoretical framework for research. In: LESTER F. K. (Ed.). Second handbook of research on mathematics teaching and learning. Charlotte, NC: Information Age Publishing, 2007. p. 629-667.

MINISTÉRIO DA EDUCAÇÃO E CIÊNCIA. Metas curriculares do ensino básico - Matemática. Primeira Edição. Lisboa: MEC, 2012.

MINISTÉRIO DA EDUCAÇÃO E CIÊNCIA. Programa de matemática para o ensino básico. Primeira Edição. Lisboa: MEC, 2013.

LIVY, S.; VALE, C. First year pre-service teachers' mathematical content knowledge: Methods of solution for a ratio question. Mathematics Teacher Education and Development, Nova Zelândia, v. 13, n. 2, p. 22-43. 2011.

LO, J.; CAI, J.; WATANABE, T. A comparative study of the selected textbooks from China, Japan, Taiwan and the United States on teaching of ratio and proportion concepts. In: ANNUAL MEETING OF THE NORTH AMERICAN CHAPTER OF THE INTERNATIONAL GROUP FOR THE PSYCHOLOGY OF MATHEMATICS EDUCATION. $23^{\text {rd }}$, 2001, Utah. Proceedings... Colombus, OH: The Ohio State University, 2001. p. 509-520.

SCOTT, P.; MORTIMER, E.; AMETLLER, J. Pedagogical link-making: a fundamental aspect of teaching and learning scientific conceptual knowledge. Studies in Science Education, Londres, v. 47, n. 1, p. 3-36, Mar. 2011.

SHULMAN, L. S. Those who understand: Knowledge growth in teaching. Educational Researcher, Washington, v. 15, n. 2, p. 4-14, Feb. 1986.

SINGH, P. Understanding the concepts of proportion and ratio among grade nine students in Malaysia. Internacional Journal of Mathematical Education in Science and Technology, Londres, v. 31, n. 4, p. 579-599, Aug. 2000.

SUGGATE, J.; DAVIS, A.; GOULDING, M. Primary mathematical knowledge for primary teachers. 3. Ed. Londres: David Fulton Publishers, 2006. 